\title{
RETRACTED ARTICLE: Habits, Priming and the Explanation of Mindless Action
}

\section{Ezio Di Nucci ${ }^{1}$}

Received: 13 June 2016/Accepted: 28 November 2016/Published online: 28 December 2016

(C) Springer Science+Business Media Dordrecht 2016

The author has retracted this article because it shows significant overlap with a previous publication by the same author [1]. This article is therefore redundant. Although the author acknowledged and referenced the monograph in the article, the author misunderstood the practice of re-using one's own material and apologizes for any inconvenience caused. The author agrees to this retraction.

The online version of this article contains the full text of the retracted article as electronic supplementary material. 1. Di Nucci, E. (2013). Habits, Priming, Aliefs and the Explanation of Action. In Mindlessness (pp. 18-43). Newcastle upon Tyne: Cambridge Scholars Publishing.

Electronic supplementary material The online version of this article (https://doi.org/10.1007/s11023016-9410-5) contains supplementary material, which is available to authorized users.

Ezio Di Nucci

ezio@sund.ku.dk

1 University of Copenhagen, Copenhagen, Denmark 